\title{
Labor Market as a Factor of Sustainable Development of the Coal Mining Region
}

\author{
Zhanna Ozderbiyeva ${ }^{1}$, and Olga Shershneva ${ }^{1}$ \\ ${ }^{1}$ Kemerovo state university, 650000, 6 Krasnaya st., Kemerovo, Russia
}

\begin{abstract}
The article examines the labor market as a factor of sustainable development. It substantiates that sustainable development of the coal mining region is possible if there is an effective labor market, which is characterized by the correlation of the demand for labor and its supply, decent work and the level of wages relevant to the needs of the able-bodied population. This places demands on the quality of the workforce and the provision of efficient employment. The authors revealed the relationship between the sustainable development of the regional economy and the labor market.
\end{abstract}

\section{Introduction}

The economic development of the country, including the region, is a multifaceted process, which is characterized by changes in quantitative and qualitative characteristics. There are several approaches to considering the concepts of sustainability and development: from the point of view of a systematic approach, from the point of view of other approaches that rely on various research criteria (for example, environment and development). Based on a systematic approach, it can be noted that the concepts of sustainability and development are interrelated. For the concept of sustainability, it also should be considered as a multifaceted phenomenon that may change depending on the chosen research objectives.

The concept of sustainable development has recently acquired particular relevance in connection with the global challenges of the time and growing social, economic, and political contradictions. Since labor is the basis of human life, therefore, it will be the basis for achieving sustainable development. The progressive development of the economy is impossible without ensuring decent work for the able-bodied population in order to reproduce a high-quality workforce. In modern conditions, "decent work" is "a common global goal adopted by large regional associations, global organizations and included in many declarations of human rights and development strategies" [1].

The Russian labor market is characterized by uneven development due to the regional and gender factors. This can pose a threat not only to the national economy, but also to the regional one. Therefore, in our opinion, it is important to pay special attention to the consideration of the labor market as a factor of sustainable development of the coal mining region by the example of Kuzbass. The issues of productive employment and the provision of decent work are gaining particular relevance. It should be noted that work is important for a person not only as "a means of providing income for food, housing, clothing, education and health care, it also provides an opportunity to gain knowledge and skills, social relations and 
integrate into the community" [1]. This is also confirmed by modern requirements for the quality of the labor force, which determine the objective need to receive a decent wage, which will increase the innovative activity of economic entities. The most important factor in the innovative activity of economic entities is the effectiveness of "human capital" [2].

\section{Materials and Methods}

Unemployment and employment of the population are among the most important macroeconomic problems that directly and strongly affect not only every person, but also the economy of the region and the country as a whole. In the modern world, the loss of a job for the majority of the population means a decrease in the quality of life, a loss of social status, and a decrease in competitiveness in the labor market.

The consequences of unemployment are great: it leads to the waste of labor, a reduction in GDP and national income of the country. Undoubtedly, with insufficient labor force, the economic system works ineffectively, i.e. labor resources are not used rationally. Therefore, the unemployment rate is used as one of the main indictors for assessing the state of the country's economy. Thus, the study of unemployment as a macroeconomic phenomenon and its regulation at all levels is relevant in modern conditions.

The digitalization of the economy has changed its structure, which affected the structure of employment. This is manifested in increasing the number of people employed in trade, social sphere, construction and other sectors of the non-productive sphere. The educational level of employees is of great importance in all areas. Previously, the jobs in the coal, metallurgical and other sectors of the industry was considered unskilled, but now this work also requires a high level of knowledge and skills. All this is associated with a radical technological re-equipment of almost all industries, including trade, housing and communal services and infrastructure industries. Consequently, at the regional level, the labor market is not sufficiently provided with qualified personnel with the skills to work with complex machinery and equipment, as well as blue-collar workers. In addition, the automation of technological processes carries risks for the older generation of workers, as they experience difficulties in mastering new equipment [3]. As some authors note, the main burden of economic modernization falls on labor markets, thereby creating conditions for destroying the principles of social justice in the distribution of labor income [4].

To assess the labor market as a factor in the sustainable development of the region, it is necessary to analyze such social-and-economic indicators as, the employment rate, the unemployment rate, the level of wages, which are presented in Table 1.

Table 1. Indicators of the labor market of Kuzbass [1].

\begin{tabular}{|c|c|c|c|c|}
\hline & $\mathbf{2 0 1 7}$ & $\mathbf{2 0 1 8}$ & $\mathbf{2 0 1 9}$ & $\mathbf{2 0 2 0}$ \\
\hline Employment rate, \% & 56 & 56.1 & 55.6 & 54.7 \\
\hline Unemployment rate, \% & 7.1 & 6.1 & 5.5 & 6.7 \\
\hline Average wages, rubles & 32648 & 38023 & 41770 & 43435 \\
\hline
\end{tabular}

\section{Results and Discussion}

The functioning of the labor market involves the analysis of employment and unemployment rates to assess the sustainability of the social-and-economic development of the region. Changes in the dynamics of unemployment rate affect not only the dynamics, but also the 
structure of the employed population. During the study period from 2017 to 2020 , the employment rate averaged was 54.8\%. The unemployment rate decreased from 2017 to 2020 from $7.1 \%$ to $5.5 \%$, and during the pandemic it increased to $6.7 \%$.

The most developed industries in the region are trade, mining and manufacturing, transport, education and healthcare. This is confirmed by the fact that the largest number of employees for the period 2017-2019 is concentrated in such industries as: wholesale and retail trade $(15.5 \%)$, manufacturing $(11.7 \%)$, mining $(9.8 \%)$, transportation and storage $(8.7 \%)$, education $(8.7 \%)$, healthcare $(7.9 \%)$.

Let us consider the structure of the employed population by gender. In the region as a whole, the number of employed men exceeds the number of employed women in the period from 2017 to 2019 by 17 thousand, 28.9 thousand, 35.2 thousand people, respectively, by year. As we can see, the trend of exceeding persists and even increases: in 2019, the increase was more than 2 times in comparison with 2017.

In the extraction industries for the period 2017-2019 the number of employed men and women increased: men (by 8.9 thousand in 2018, by 9.1 thousand in 2019); women (by 1.8 thousand in 2018, by 1.5 thousand in 2019). Figure 1 shows the dynamics of the share of men and women employed in the industry [5].

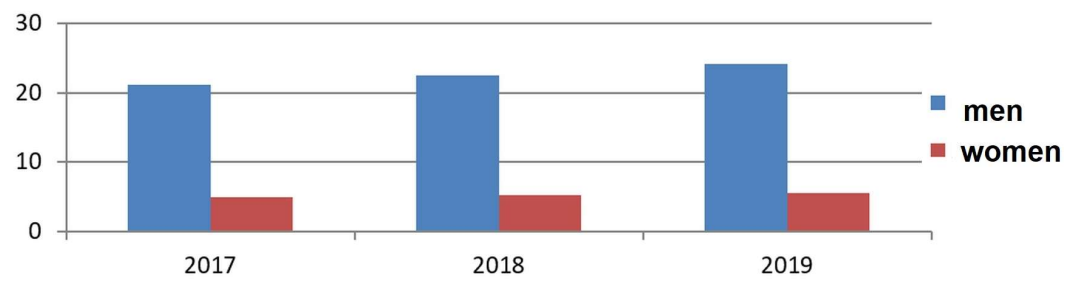

Fig. 1. The share of men and women employed in the mining industry, $\%$.

Let us note the industries in which the number of women exceeds the number of men (from 2017 to 2019; people):

- wholesale and retail trade; repair of motor vehicles: by 56.1 thousand, 52 thousand, 49.5 thousand; employed women in this industry are 2 times more than men;

- hotels and public catering business: by 13.4 thousand, 12.4 thousand, 18.1 thousand; in 2017, the share of women is 3.5 times higher than that of men, and in 2020 - 7 times;

- financial and insurance spheres: by 9.1 thousand, 12.4 thousand, 9.5 thousand; from 2017 to 2020 , the excess of the share of employed women over the share of employed men changed from 3 to 2.5 times;

- professional, scientific and technical activities: by 6.6 thousand, 3.4 thousand, 3.7 thousand; the share of women employed in this area is 2 times more than the share of men;

- education: 82.2 thousand, 82.5 thousand, 76.6 thousand; in 2017, the share of employed women exceeded the share of men 5 times, and in 2020 - 6 times.

- activities in the field of health care and social services: 74.7 thousand, 75.7 thousand, 76.5 thousand; in this area, the share of women exceeds the share of men by 8.6 times in 2017 , and by 7 times in 2020 ;

- activities in the field of culture, sports, organization of leisure and entertainment: by 10.3 thousand, 6.5 thousand, 8.8 thousand; the excess of the share of women over the share of men was 2.5 times. The dynamics of the share of employed men and women by industry is shown in Figure 2 [5]. 


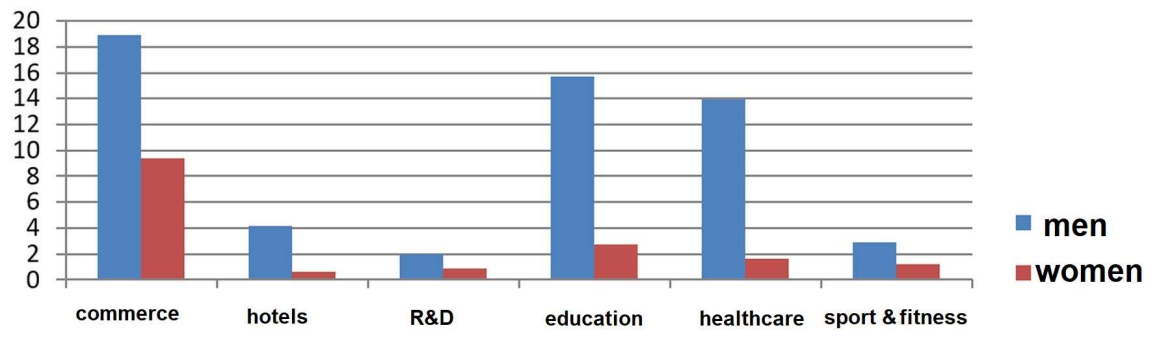

Fig. 2. Dynamics of the share of employed men and women in $2020, \%$.

Thus, there are industries in which predominantly female labor is concentrated, which is due to the historical and cultural level of development of the region. In the extractive industries, manufacturing industries, in the field of transport, etc., mostly men work.

Analysis of the employed population by age groups for the analyzed period showed the following:

- up to 20 years: the dynamics is practically stable and amounts to $0.5 \%$;

- 20-29 years: decreased by $1.8 \%$ (2018) and $1.2 \%$ (2019);

- 30-39 years old: in 2018 increased by $0.6 \%$ and in 2019 by $0.6 \%$;

- 40-49 years: an increase in the employed by $0.8 \%$ and $0.8 \%$;

- 50-59 years: an increase by $0.5 \%$ (in 2018), and in 2019 - a decrease by $0.2 \%$;

- 60 and over: unchanged in 2018, in 2019 - an increase by $0.9 \%$. The structure of the employed population by age group is shown in Figure 3 [5].

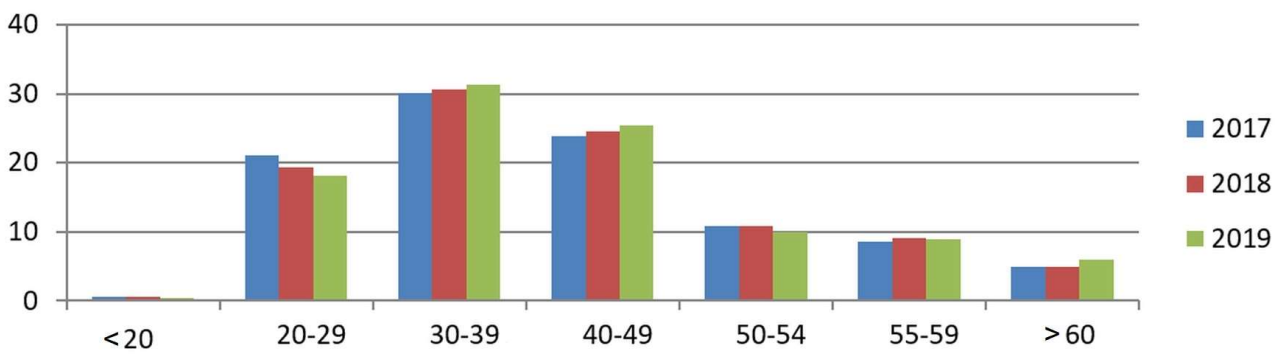

Fig. 3. The structure of the employed population by age groups, $\%$.

At the same time, the average age for this period increased by $0.7 \%$ and amounted to 40.8 years. Traditionally, the most able-bodied labor force is considered to be in the 30-50 age group. Based on the considered dynamics, it can be concluded that there is a positive dynamics of the employed in the indicated age groups. Consequently, this can be viewed as a source of growth in labor productivity and, accordingly, gross regional product [6-8].

The structure of the employed by gender and occupation group did not change significantly from 2017 to 2019. Let us rank the groups of employed in descending order of their share in the total number of employed:

- the largest share in the number of employees was made by operators of production plants and machines, assemblers and drivers $(18.6 \%, 19.2 \%, 20.7 \%)$. In this group, the share of men $(31.5 \%, 32.4 \%$, and $35 \%)$ significantly (almost 6 times) exceeds the share of women $(5.4 \%$, $5.4 \%$, and $5.7 \%$ ).

- specialists of the highest qualification level $(17.1 \%, 17 \%, 17.7 \%)$. In this group, the largest share of the employed was women $(26.6 \%, 26.2 \%$, and $25.8 \%)$, which is $2-3$ times higher than the share of men $(7.8 \%, 8.2 \%$, and $10 \%)$. 
- workers in the service sector and trade, protection of citizens and property $(15.2 \%, 15.6 \%$ $15 \%)$. In this group, the proportion of women is approximately 3 times higher than that of men. Women $(23 \%, 23.7 \%$, and $23.7 \%)$, men $(7.7 \%, 7.8 \%$, and $6.9 \%)$.

- skilled workers in industry, construction, transport and related occupations $(15 \%, 15.9 \%$, and $14.5 \%)$. The share of men $(25.7 \%, 26.5 \%$, and $23.4 \%)$ is almost 6.5 times higher than the share of employed women ( $4 \%, 4.7 \%$, and $5 \%)$.

- the next place is occupied by specialists with a middle qualification level $(11.4 \%, 11.2 \%$, $11.3 \%)$, where the share of women $(14.9 \%, 14.6 \%$, and $14.6 \%)$ exceeds the share of men by almost 2 times $(7.9 \%, 8 \%$, and $8.1 \%)$.

- unskilled workers in this ranking occupy: $10.3 \%, 9.6 \%$, and $9.4 \%$. In this group, the share of women $(11.4 \%, 11.3 \%$, and $11 \%)$ also prevails over men $(9.3 \%, 9.6 \%$, and $7.8 \%)$.

- executives: $8.1 \%, 7.3 \%, 7.3 \%$. In this group, there remains a slight gap between the proportion of men $(8.6 \%, 7.4 \%$, and $7.2 \%)$ and women $(7.5 \%, 7.3 \%$, and $7.3 \%)$.

- a small share of the employed is occupied by employees engaged in the preparation and execution of documentation, accounting and maintenance: $3.5 \%, 3.1 \%$, and $3 \%$. In this group, the share of women $(6.4 \%, 5.8 \%$, and $5.6 \%)$ is 9 times higher than the share of men $(0.7 \%, 0.5 \%$, and $0.6 \%)$. We can say that only women work in this group.

- the smallest share of the employed belongs to the group of skilled workers in agriculture, forestry, fish farming and fishing: $0.8 \%, 1.1 \%$, and $1.1 \%$. In this group, the share of employed men $(0.8 \%, 1.2 \%$, and $1 \%)$ and women $(0.8 \%, 1.2 \%$, and $1.3 \%)$ is approximately equal. Figure 4. shows the structure of the employed by education level.

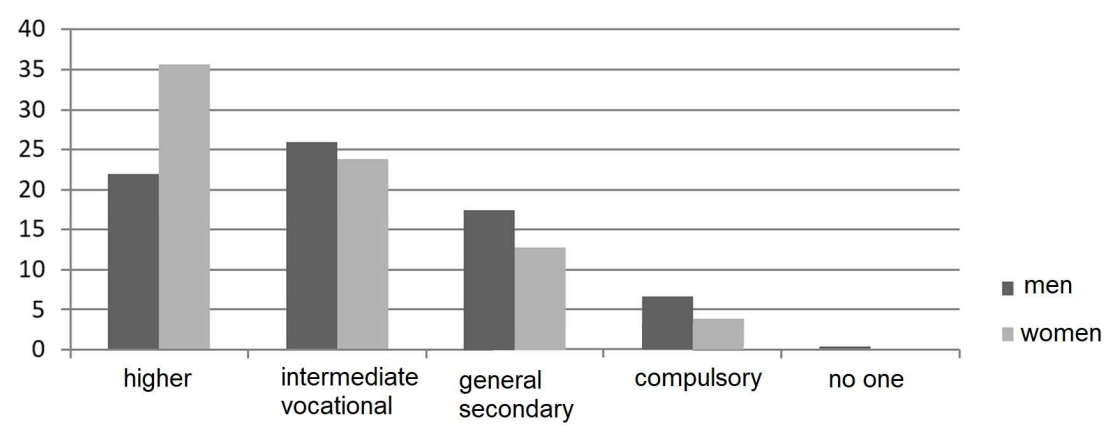

Fig. 4. The structure of the employed by education level among employed men and women, average value for the period $2017-2019, \%$.

If we focus on the ratio of the share of employed men and women, then the share of employed men is higher in the first and fourth groups. Whereas the second, third, fifth, sixth and eighth groups show a predominance of the share of employed women. The gap between the shares of employed men and women is leveled in the seventh and ninth groups.

An analysis of the labor market would be incomplete without considering data on the unemployment rate, an increase in which is a threat to the sustainable development of the region. Therefore, it is important to consider this indicator in dynamics, taking timely measures to regulate its level.

Regional unemployment has an uneven dynamics, if we consider the various criteria that characterize the labor force. So, it can be observed in the range of age groups from 20 to 50 years (Figure 5). This can be explained by the fact that for young people work experience is required that they do not have. For the older group of the working-age population, unemployment is due to such reasons as finding a job with better working conditions, in accordance with professional experience and skills, and higher wages. 


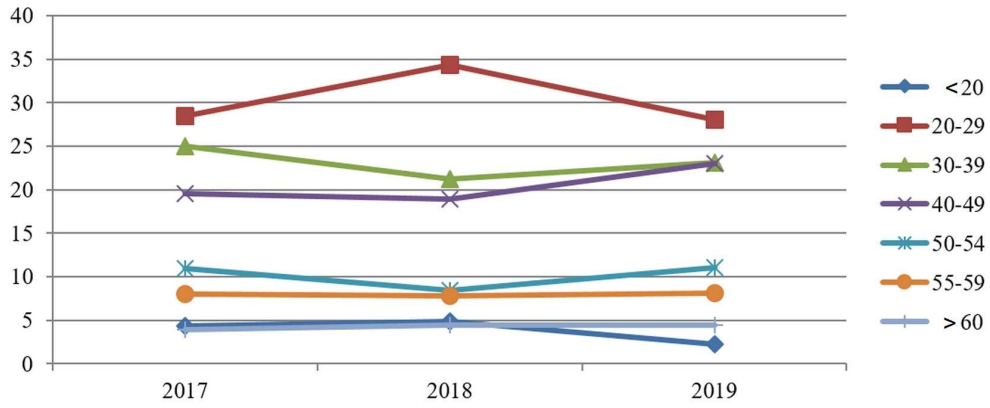

Fig. 5. The structure of unemployed by age group, in $\%$ of the total.

It should be noted that in terms of gender, unemployment by age group has insignificant differences. In 2019, among men, the largest share fell on the age of 20-29 years $(30.9 \%)$, and among women - 30-39 years (26\%). Unemployment for women of this age is due to the high burden of family functions that they have to perform, so for employers they are a burdensome workforce. The high percentage of unemployed among men aged 20-29 can be explained by the fact that they have excessive requirements for wages, which is partly due to family functions, striving for career growth, etc.

Any processes taking place in the external environment have an impact on the labor market immediately. The consequences of such an impact may be different, and not always positive [9-10]. This is primarily manifested at the levels of wages of the working-age population. For the region, the problem of inequality in wages is not a new trend, but a natural one due to the sectoral characteristics and regional differences.

Table 2. Average monthly nominal wage of workers in the Kemerovo region by the type of economic activity for 2018-2020, rub.

\begin{tabular}{|c|c|c|c|}
\hline & 2018 & 2019 & 2020 \\
\hline Total & 38023 & 41770 & 43435 \\
\hline mining activity & 57868 & 61396 & 60831 \\
\hline $\begin{array}{l}\text { professional, scientific and } \\
\text { technical activities }\end{array}$ & 50903 & 54855 & 55770 \\
\hline financial and insurance activities & 50238 & 54394 & 55074 \\
\hline $\begin{array}{l}\text { public administration and military } \\
\text { security; social security }\end{array}$ & 46029 & 50695 & 53680 \\
\hline transportation, storage & 38692 & 42415 & 43199 \\
\hline manufacturing industries & 38146 & 41879 & 43355 \\
\hline constraction & 36603 & 43512 & 43486 \\
\hline $\begin{array}{l}\text { activities in the field of health and } \\
\text { social services }\end{array}$ & 33862 & 36360 & 41083 \\
\hline education & 29092 & 32169 & 35048 \\
\hline $\begin{array}{l}\text { agriculture, forestry, hunting, } \\
\text { fishing and fish farming }\end{array}$ & 22643 & 26206 & 28407 \\
\hline
\end{tabular}


According to the data in Table 2, one can note a significant differentiation in wages by the type of economic activity. In the table, the rating of industries by the size of wages is built, from the highest value to the lowest. Therefore, the gap between the levels of wages in mining and in agriculture, forestry, hunting, fishing and fish farming was 2.5 times in 2018, and 2 times in 2020. Such industries as education, health care, agriculture and forestry have persistently low wages for decades, since they are not export-oriented and monopolistic, like mining. At the same time, wages in agriculture and forestry in 2020 are 1.5 times less than the average for the region's economy; in education, it is 1.2 times less.

\section{Conclusion}

Based on the study of the economic situation in the region's labor market, it can be noted that it operates in difficult macroeconomic conditions. They become sources of the following problems, which can become threats to the sustainable development of the region: uneven changes in employment of the population in various types of economic activities (agriculture, construction, manufacturing), by age and gender, differentiation of wages by industry. All this makes the situation on the regional labor market alarming.

To ensure effective employment of the population, it is necessary to apply the following set of measures:

1. Development and encourage of large and small businesses in order to create new and additional jobs.

2. Joint activities of educational organizations and employers in order to bring supply and demand in the labor market into line.

3. Improvement of the regulatory framework for the adjustment of labor and wages.

4. Strengthening measures for the adaptation of persons who find themselves in a difficult social-and-economic situation because of job loss.

5. Continuous professional training and retraining of personnel.

In this regard, there are several directions for the implementation of measures that will reduce the consequences of macroeconomic instability in the coal mining region:

- long-term investment in education and training to improve the quality of the workforce;

- support for industries that ensure sustainable economic growth, which will create favorable conditions for increasing the demand for workers in various sectors of the economy;

- strengthening the competitiveness of the region through the formation of effective labor potential.

At the present stage, the state program of the Kemerovo region "Promotion of population employment in Kuzbass" for 2014-2020 is in effect. The goal of the program is to prevent the growth of tensions in the labor market, to help preserve the health of workers and to ensure the protection of the labor rights of citizens. The objectives of the state program are: - ensuring affordable and high-quality provision of public services in the field of promoting employment of the population;

- organization of the resettlement process to the Kemerovo region of compatriots living abroad, their employment, arrangement and adaptation in the territory of resettlement;

- certification of workplaces for working conditions;

- implementation of preventive measures to reduce occupational injuries and occupational morbidity.

The implementation of these tasks is aimed at:

- preventing the growth of tension in the labor market by minimizing the levels of general and registered unemployment;

- implementation of state guarantees of social support for unemployed citizens in a timely and full manner;

- ensuring the preservation of the health of employees by improving their working conditions. 
Thus, in order to limit the negative impact on the labor market, ensure the growth of the life quality of the population, and in order to fully implement the strategic plans for the socialand-economic development in the Kemerovo region, coordinated actions of executive authorities, local governments, vocational education institutions, employers, interested organizations are necessary.

The implementation of the goals of sustainable development in the region is impossible without the use of a systematic approach. As noted above, work and employment are fundamental to achieving the goal of sustainable development. To achieve sustainable development, it is necessary to provide all working-age population with decent work. In this context, it is necessary to develop legislation aimed at achieving sustainable development of the labor market. This requires a retrospective and prospective analysis of the regional labor market.

\section{References}

1. D.F. Frey, G.A. MacNaughton, SAGE Open, 6(2), 958DOI: $10.1177 / 2158244016649580$.

2. C. Goldin L. Katz, The Race between Education and Technology (UP, Princeton, 2009)

3. C. Degryse, Digitalization of the economy and its impact on labor markets (ETUI, Brussels, 2016)

4. T. Bussemer, C. Krell, H. Meyer, Social Europe Occasion paper, 10, 19 (2016)

5. The official website of the territorial body of the Federal State Statistics Service for the Kemerovo Region-Kuzbass. URL: https://kemerovostat.gks.ru/folder/38679

6. A.N. Tokarev, Economics and Innovation Management, 3, 46-51 (2017) DOI: 10.26730/2587-5574-2017-3-46-51

7. N.K. Sedykh, I.N. Tchaikovskaya, Economics and Innovation Management, 1, 74-83 (2021) DOI: 10.26730/2587-5574-2021-1-74-83

8. T.V. Kiseleva, V.G. Mikhailov, Ya.S. Mikhailova, Economics and Innovation Management, 1, 63-73 (2021) DOI: 10.26730/2587-5574-2021-1-63-73

9. O.E. Kalenov, S.N. Kukushkin, Economics and Innovation Management, 3, 88-96 (2020) DOI: 10.26730/2587-5574-2020-3-88-96

10. A.N. Tokarev, Economics and Innovation Management, 1, 25-35 (2018) DOI: $10.26730 / 2587-5574-2018-1-25-35$ 